\title{
Sexual size dimorphism and male reproductive traits vary across populations of a tropical rainforest dung beetle species (Onthophagus babirussa)
}

\author{
Kai Xin Toh ${ }^{1}$, Sean Yap ${ }^{1}$, Thary Goh ${ }^{2}$, and Nalini Puniamoorthy ${ }^{1}$ \\ ${ }^{1}$ National University of Singapore \\ ${ }^{2}$ University of Malaya
}

July 2, 2021

\begin{abstract}
Sexual size dimorphism (SSD) arises when natural selection and sexual selection act differently on males and females. Rensch's rule predicts that SSD increases with body size in species when males are the larger sex. However, male-biased SSD is rare in insects and the rule does not always hold between species and even among populations. Here, we investigate intra-specific variation in SSD as well as relative investment in precopulatory (horn length) and postcopulatory traits (sperm length and testes weight), in a tropical rainforest dung beetle Onthophagus babirussa across Singapore and Peninsular Malaysia. Overall, three out of four populations displayed significant male-biased SSD but contrary to Rensch's rule, SSD was greater in populations with smaller overall body size. Average male body size was similar across all populations, but female body size differed significantly suggesting that the pronounced SSD may also be due to weaker fecundity selection on female body size. Across all populations, horn length showed a strong positive static allometry while postcopulatory traits showed negative allometry (in all but one population), which suggests an evolutionary trade-off between precopulatory and postcopulatory traits in this species.
\end{abstract}

Sexual size dimorphism and male reproductive traits vary across populations of a tropical rainforest dung beetle species (Onthophagus babirussa)

Toh Kai Xin^ ${ }^{1}$, Sean Yap^^${ }^{\wedge}$, Thary Gazi Goh ${ }^{2}$, Nalini Puniamoorthy*1

${ }^{1}$ Department of Biological Sciences, National University of Singapore, 16 Science Drive 4, Block S3 Level 4, Singapore 117558

${ }^{2}$ Institute of Biological Sciences, Science Faculty, University of Malaya, 50603, Kuala Lumpur, Malaysia

*Corresponding author: nalini@nus.edu.sg

\section{Abstract}

Sexual size dimorphism (SSD) arises when natural selection and sexual selection act differently on males and females. Rensch's rule predicts that SSD increases with body size in species when males are the larger sex. However, male-biased SSD is rare in insects and the rule does not always hold between species and even among populations. Here, we investigate intra-specific variation in SSD as well as relative investment in precopulatory (horn length) and postcopulatory traits (sperm length and testes weight), in a tropical rainforest dung beetleOnthophagus babirussa across Singapore and Peninsular Malaysia. Overall, three out of four populations displayed significant male-biased SSD but contrary to Rensch's rule, SSD was greater in populations with smaller overall body size. Average male body size was similar across all populations, but female body size differed significantly suggesting that the pronounced SSD may also be due to weaker fecundity selection on female body size. Across all populations, horn length showed a strong positive static 
allometry while postcopulatory traits showed negative allometry (in all but one population), which suggests an evolutionary trade-off between precopulatory and postcopulatory traits in this species. (183 words)

Keywords : Sexual size dimorphism, Dung beetle, Southeast Asia, Rensch's rule, Reproductive evolution, Sexual selection

\section{Introduction}

Sexual selection is defined as selection on heritable traits that vary between individuals within a population that influence reproductive success and fitness (Andersson, 1994). When individuals within a population have differential reproductive success (Panhuis et al., 2001), this can occur prior to copulation (precopulation), when males compete for access to females, leading to evolution of sexual dimorphism in size and secondary sexual traits such as ornaments and weapons (Simmons \& García-González, 2008). Sexual selection can also occur postcopulation, for example in the form of cryptic female choice, where females can influence the success rate of insemination by males and/or via sperm competition, where sperm from different males compete to fertilise the ova (Birkhead \& Pizzari, 2002).

One of the most common traits that is subject to sexual selection is body size. Sexual size dimorphism (SSD) arises when the effects of natural selection and sexual selection act differently on males and females (Blanckenhorn, 2005). In fact, across species, when males are larger, SSD is predicted to increase with overall body size, but decreases with size when females are larger (sensu Rensch's rule) (Rensch, 1959). This phenomenon has been well documented across numerous taxa especially vertebrates (Fairbairn 1997; Dale et al. 2007; Székely et al. 2004). However, in most invertebrates, such as insects, species often display femalebiased SSD, where females are larger due to strong fecundity selection. Larger male body size is usually a derived trait in most insect lineages and numerous species present exceptions to the rule (Blanckenhorn et al 2004; Blanckenhorn, Meier \& Teder, 2007). For instance, SSD can even vary significantly within a species but not many studies address population differences in SSD (Teder \& Tammaru, 2005; Cox \& Calsbeek, 2010; Puniamoorthy et al. 2012; Liao, Liu \& Merilä, 2015; Piross et al 2019; Rossi and Haga 2019).

Species belonging to the dung beetle genus, OnthophagusLatreille, 1802, the most species rich genus in the animal kingdom, have been gaining increased interests as models in sexual selection research because many species display strong sexual dimorphisms (Parzer \& Moczek, 2008). Males often possess horns, a precopulatory sexual trait, on the head and/or thorax which are used in defending breeding tunnels occupied by females (Garcia-Gonzalez \& Simmons, 2011; Kijimoto et al., 2009; Simmons \& García-González, 2008). For instance, in certain Onthophagus species, male horn lengths might trade-off with male investment in testes and sperm and even maternal effects, such as larval food provisioning, could affect variation in these male phenotypes (Emlen, 1994; Emlen, 1997a; Moczek, 1998; Silva et al., 2016). These studies often include work on O. taurus (Schreber, 1759), native to the Mediterranean and exotic ranges in Eastern and western North America and Australia, and O. acuminatus Harold, 1880, native to Central America (Emlen, 1994; Emlen, 1997a; Moczek, 1998; Silva et al., 2016). However, there is relatively little information on population-level differences in reproductive trait variation in Southeast Asian Onthophagus species (Parrett \& Knell, 2018; Parrett et al., 2019; Parrett et al., 2021). Previous reports on AsianOnthophagus species do not report male-biased SSD among species (Goh \& Hashim, 2020; Pomfret \& Knell, 2006) but preliminary surveys in Singapore indicated that there were some species where wild-caught males were consistently larger than females. Here, we study variation in SSD in one such species: Onthophagus babirussa (Coleoptera: Scarabaeidae; Eschscholtz, 1822) which is a widespread species across SEA (Goh, 2014; Kudavidanage, Qie, \& Lee, 2012; Priawandiputra et al. , 2020; Toh, 2019). Specifically, we investigate variation in both precopulatory and postcopulatory traits within and between four different populations from Singapore and Peninsula Malaysia.

We used DNA barcoding to confirm the genetic distinction of $O$.babirussa from morphologically similar species such as $O$.rufiobscurior Ochi, Kon and Tsubaki, 2009 and assess genetic variation across all sampling sites. We tested if SSD varies among populations and if this difference between the sexes increased with body size (sensu Rench's rule). In addition, we investigated male investment in a precopulatory trait (horn length) and postcopulatory traits (testes weight and sperm length) by calculating static allometry, a widely used 
tool in quantifying relative investment in traits as a function of body size (Eberhard et al. , 2018). Prior studies suggest that there may be potential trade-offs in the investment of precopulatory and postcopulatory traits given the limited resources for development (Moczek \& Nijhout, 2004). As beetle horns are important in mate acquisition (Simmons \& Ridsdill-Smith, 2011), we tested the hypothesis that there would be a high investment in beetle horns, hence a positive allometry and that the allometric coefficient for postcopulatory traits would be lower than that of horns.

\section{Materials and methods}

\subsection{Dung beetle sampling}

\subsubsection{Study Sites}

Dung beetles examined in this study were sampled in Singapore and Peninsular Malaysia. Figure 1 depicts a map of all sampling sites, and a full list coordinates are appended in a supplement to the main manuscript (Appendix 1: Table S1). Sampling in Singapore spanned over fifteen months from August 2018 to February 2018 and May 2019 to December 2019. Specimens from Malaysia were sampled across four sites, Perak, Gombak, Kenyir and Langkawi, from August to November 2016, and July 2019. Beetles from sites A, B, C and D were pooled because these sites were part of a continuous stretch of forest in the central region of Singapore. Sites G, H and I are mainland Malaysia sites that are closer to one another than they are from the others and they were pooled due to sample limitations. Furthermore, based on mitochondrial haplotypes (Appendix 2), genetic variation of Onthophagusbabirussa was panmictic and samples from sites G, H and I were genetically similar to each other, further justifying our grouping of the three sites as a representation of mainland Peninsular Malaysia. Site E (Pulau Ubin) and F (Langkawi) were both island populations, separated from mainland Singapore and Peninsular Malaysia respectively. Potential limitations from pooling the population were also taken into account during statistical analyses in section 2.4.

\subsubsection{Sampling, sorting and preservation protocol}

Dung beetle sampling was conducted using baited pitfall traps and baited funnel pitfall traps with human dung as the bait because it is widely accepted to be the best bait to attract dung beetles (Howden \& Nealis, 1975; Kudavidanage et al., 2012; Larsen \& Forsyth, 2005). Exact details of trap materials and construction are appended (Appendix, Figure S1). Traps were retrieved after 24 to 48 hours, and captured beetles were brought back to the laboratory for morphological identification and sorting using an Olympus SZX10 microscope.

Onthophagus . babirussa were separated from other species via their distinct thorax patterning. Specifically, the lateral portions on both sides of the thorax are in a lighter shade of brown compared to rest of thorax and contain one or two darker brown spots (Appendix, Figure S2 \& S3). Mid femurs of all individuals were dissected for molecular work (see below) and male $O$. babirussaindividuals were separated from females based on the presence of head horns. Male individuals were kept in separate, labelled Eppendorf tubes with a drop of $1 \mathrm{x}$ Phosphate-Buffered solution (PBS).

\subsubsection{Molecular sorting and investigating genetic variation}

DNA was extracted from 739 specimens from Singapore populations $(\mathrm{CCNR}=129$ and Pulau Ubin=167) and Malaysian populations (Central Peninsular MY=109 and Langkawi=334). The cytochrome oxidase I gene (COI) fragment has been widely used as to distinguish and identify species for most animals as the mutation rate of COI gene is approximately parallel to speciation time scale, thus able to differentiate between species that are closely related (Fraija-Fernández et al., 2018; Hebert et al., 2003; Waugh, 2007). Furthermore, the COI gene is an ideal species marker for insects due to the simple sequence alignment, primer sites that are robust and easily available and low likelihood of recombination and possession of introns (Foottit \& Adler, 2009). A 3\% threshold for uncorrected pairwise distances was used as it is commonly used in literature to differentiate species (Hebert et al., 2003; Meiklejohn, Wallman, \& Dowton, 2011; Srivathsan \& Meier, 2012).

For all specimens, the right mid femur was dissected into $7 \mu \mathrm{l}$ of QuickExtract solution and the DNA was extracted by following Lucigen's (the manufacturer's) protocol (Lucigen, 2018). After DNA extraction, COI 
amplification was conducted on extracted DNA. The reaction volumes for COI amplification for each sample was $5 \mu$ l of CWBIO 2xTaq MasterMix (Dye), $1 \mu \mathrm{l}$ of extracted DNA, $1 \mu \mathrm{l}$ of sterilised Millipore water, $1 \mu \mathrm{l}$ of forward primer, "mlCOIintF": 5'- GGW ACW GGW TGA ACW GTW TAY CCY CC-3' (Leray et al., 2013), $1 \mu \mathrm{l}$ of reverse primer, "jgHCO2198": 5'-TAN ACY TCN GGR TGN CCR AAR AAY CA-3' (Geller et al., 2013) and $1 \mu \mathrm{l}$ of $0.001 \mathrm{mg}$ Bovine Serum Albumin (BSA). Polymerase Chain Reaction (PCR) was performed using the Eppendorf Mastercycler nexus gradient using a step-up cycling protocol. The following protocol was used: initial denaturation $\left(94^{\circ} \mathrm{C}, 5\right.$ minutes) followed by 35 cycles of denaturation $\left(94^{\circ} \mathrm{C}, 1\right.$ minute), annealing $\left(47^{\circ} \mathrm{C}, 2\right.$ minutes $)$ and extension $\left(72^{\circ} \mathrm{C}, 1\right.$ minute) and lastly, final extension $\left(72^{\circ} \mathrm{C}, 5\right.$ minutes). In addition, primers were labelled with a sequence tag of 7-9bp such that all specimens will have a unique combination of labelled forward and reverse primers. The successfully amplified PCR products were pooled and sent for NGS sequencing, and sequences were analysed by constructing a cluster fusion diagram using uncorrected pairwise distances. The full sequencing and bioinformatics pipeline is appended in Appendix2.

In order to estimate gene flow between populations, a haplotype map was constructed for the COI sequences of approximately 306 base pairs, with 434 specimens of $O$. babirussa from Singapore and Malaysia populations. A minimum spanning network with the software PopART was used to examine haplotypes and their geographical distribution (Leigh \& Bryant, 2015). The haplotype map is appended in Appendix2 (Figure S4).

The results of the molecular investigation showed that morphologically sorted $O$. babirussa were genetically distinct from other similar looking morphospecies, lending support to our morphological sorting. The haplotype map also showed that populations across all sampling sites were panmictic, justifying our groupings of mainland peninsular Malaysia sites.

\subsection{Documenting reproductive trait variation}

\subsubsection{Precopulatory trait measurements}

To investigate the sexual size dimorphism in the four populations of $O$. babirussa, maximum pronotum width (Figure 2) of males and females were measured as a proxy for body size with the eyepiece reticle on the Olympus SZX10 microscope. This is widely used proxy for body size because the pronotum width does not change in adulthood and has been found to be the most appropriate measure for body size in dung beetles (Emlen, 1997; Knapp \& Knappová, 2013).

Horn lengths of male O. babirussa (Figure 2) were measured to document variation in this precopulatory trait. Images were taken of the anterior habitus. Heads of the beetles were separated and suspended with Durex KY Jelly, with horns aligned parallel to the lens of the camera. Images were captured using the EOS 800D and 6D camera body with the Canon MP-E $65 \mathrm{~mm} \mathrm{f/2.8} \mathrm{1-5x} \mathrm{lens} \mathrm{at} \mathrm{5x} \mathrm{optical} \mathrm{zoom.} \mathrm{The}$ camera was suspended on the Dun, Inc. P-51 and the Camlift controller V2.9.3.0 software was used to take multiple images at different heights for focus stacking. EOS Utility Launcher software was used to access the images and stack them using the Zerene Stacker V. 1.04. software. Stacked images were imported to Adobe Photoshop CS5 V. 12.0 x64 and a 1mm scale bar was added to each image. Next, processed images were imported to ImageJ V. 1.51 and the horns were measured from the tip to the bottom of the outer edge of each horn, following previous studies (Moczek \& Emlen, 1999).

\subsubsection{Postcopulatory trait measurements of male specimens}

Abdomens of male $O$. babirussa specimens were dissected into $1 \mathrm{x}$ phosphate-buffered solution (PBS) to measure the following postcopulatory traits: testes weight and sperm length (Figure 2). Testes were isolated and transferred onto pre-weighed aluminium sheets and dried in a Memmert Gravity Basic Digital Oven D overnight. Then, total weight was measured on the Mettler Toledo ML104 Newclassic ml Analytical Balance. Weight of the testes were calculated by subtracting the weight of the aluminium sheet from the total weight.

To measure the sperm length, seminal vesicles containing the mature sperm were first isolated and transferred 
onto a drop of PBS on a frosted slide. Then, sperms were teased out from the vesicles using an insect pin. Slides were dried in the oven and sperms were fixed onto the slides with a solution of three parts methanol and one part acetic acid for two minutes. Next, the slides were washed in 1x PBS for one minute and the sperms were stained for five minutes in the dark with 4',6-diamidino-2-phenylindolev (DAPI), which binds to DNA to form a fluorescent complex to allow for visualisation of sperm heads under a fluorescent microscope. Following that, the slides were washed in 1x PBS and placed in the dark to dry. When the slides were dried completely, one to two drops of glycerol were added on the stained regions, coverslips were placed, and the edges were sealed with clear nail polish and left to dry in the dark. The sperms were visualized using an Olympus BX50 fluorescence microscope and measured using $\mu$ Manager and ImageJ V. 1.51 software. Based on previous studies, five to ten sperms were measured per specimen (García-González \& Simmons, 2007; Simmons \& Kotiaho, 2002; Werner \& Simmons, 2011).

\subsection{Statistical analyses}

Box plots of average pronotum width were constructed with confidence intervals using the $\mathrm{R}$ packages ggplot2 (Wickham, 2016),dplyr (Wickham et al. , 2020) and plotrix (Lemon, 2006) and data for the four populations were tested for normal distribution using the Shapiro-Wilk test. As the data were not normally distributed, the non-parametric Kruskal-Wallis test was conducted instead of ANOVA to determine if there were significant sexual size dimorphism within and across the four study populations of $O$. babirussa. Posthoc analyses using Dunn test were also conducted to determine which populations differ from the other for male and female body size. In addition, the sexual dimorphism index (SDI) was calculated following the formulation by Gibbons and Lovich (1990), where the size of the larger sex is divided by the size of the smaller sex. A negative sign is arbitrarily added to the SDI as the males are larger (Gibbons and Lovich, 1990).

To determine whether populations differed with respect to relative investments in precopulatory and postcopulatory traits, the static allometries were calculated by first constructing log-log scatterplots of trait size against pronotum width. We used a linear regression to assess testes size and sperm length. As the log-log scatter plot of horn length against pronotum width displayed a clear non-linear relationship, we followed the recommendations by Knell (2009) and fitted (1) linear model, (2) quadratic model, (3) cubic model and (4) breakpoint model using the $\mathrm{R}$ package segmented (Muggeo, 2008) to the pooled data with all four populations to characterise the trait size-body size relationship (see Appendix3, Figure S5). Model selection was then collected with the Akaike information criterion (AIC). The breakpoint model had the lowest AIC score for horn length (see Appendix3, Table S2), indicating that this model is the best model for explaining the relationship between the variables (Knell, 2009). Next, allometric coefficients $\left(\beta_{1}\right.$ and $\left.\beta_{2}\right)$ of the traits of interest $\left(\begin{array}{ll}y_{1} & \text { and } y_{2}\end{array}\right)$ were obtained for each population from the following equations generated by the breakpoint model:

Equation 1: $\log \left(?_{1}\right)=\beta_{1} \log \left(?_{1}\right)+$ ?

Equation $2: \log \left(?_{2}\right)=\beta_{2} \log \left(?_{2}\right)+$ ?

\section{Results}

\subsection{Variation in Sexual Size Dimorphism (SSD)}

Overall, the average body size differed significantly across the four study populations (Kruskal-Wallis; chi-squared $=64.713, \mathrm{df}=3, P<0.0001$ ) (Figure 3 ). Males were significantly larger than females in both Singapore populations (Kruskal-Wallis: CCNR: chi-squared $=18.451, \mathrm{df}=1, P<0.0001$, Pulau Ubin: chisquared $=38.501, \mathrm{df}=1, P<0.0001$ ) and Langkawi (Kruskal-Wallis; chi-squared=7.931, $\mathrm{df}=1, P<0.01$ ), indicating a clear male-biased SSD. Although males in Central Peninsula MY were also larger than females but this difference was not statistically significant (Kruskal-Wallis; chi-squared $=1.818, \mathrm{df}=1, P>0.05$ ). In addition, the SDI was more pronounced in Singapore populations (CCNR=-1.09, Pulau Ubin=-1.12; Central Peninsular MY=-1.03 and Langkawi=-1.03), even though the average body size of males in Malaysia populations are bigger than Singapore population. 
The average body size of females differed significantly among all populations (Kruskal-Wallis; chisquared $=69.037, \mathrm{df}=3, P<0.0001)$. Females from Malaysia populations were significantly larger than females from Singapore populations (post-hoc Dunn's test; Central Peninsular MY versus CCNR and Pulau Ubin: $P$ $<0.0001, P<0.0001$; Langkawi versus CCNR and Pulau Ubin: $P<0.0001, P<0.0001)$. The average body size of males also differed significantly among all populations (Kruskal-Wallis; chi-squared $=16.145, \mathrm{df}=3, P$ $<0.01$ ). Using post-hoc Dunn's test, males from Langkawi were significantly larger than males from Singapore populations (CCNR: $P<0.01$; Pulau Ubin: $P<0.01$ ) but did not differ significantly with Central Peninsular MY. Body size also did not differ significantly between the Singapore populations and Central Peninsular MY (post-hoc Dunn's test; Central Peninsular MY versus CCNR and Pulau Ubin:P >0.05) (Figure 3).

\subsection{Variation in male reproductive traits as a function of body size}

Using a log-transformed data and the breakpoint model, a hyperallometric relationship (allometric coefficient, $\beta>1$, Figure 4a, Table 1) was found between horn length and body size (pronotum width) for all four populations of $O$. babirussa (see Appendix 3 for the best fit model for each population). The adjusted R2 values for equation one of the breakpoint model were high for all four populations, signalling a strong positive correlation. In addition, 95\% confidence intervals (CI) for equation one of all populations excluded zero, ruling out the likelihood of a zero slope, indicating a significant relationship between horn length and body size. On the other hand, 95\% CI for equation two includes zero for all populations except Pulau Ubin, signalling a non-significant relationship, hence only the allometric coefficient of equation one ( $\beta 1)$ was taken into consideration. Together, these results suggest that body size is a significant factor in explaining horn length variation, where larger males have disproportionately longer horns. Interestingly, there is an overlap in CI values for all populations which suggests that there were no significant population-level differences in allometric relationships.

Next, using log-transformed data, a positive and hypoallometric relationship (allometric coefficient $\beta<1$, Figure $4 \mathrm{~b}$, Table 1) was found between testes weight and body size (pronotum width) for CCNR, Pulau Ubin and Langkawi, and a hyperallometric relationship was found for Central Peninsular MY. The adjusted $\mathrm{R} 2$ values for the linear model of all populations were low, indicating a weak correlation. In addition, the p-values of the slopes of the four linear models ( $P>0.05$, Table 1) and 95\% CI (includes zero) suggests that body size is not a significant factor in explaining testes weight variation.

Following that, using log-transformed data, a positive and hypoallometric relationship (allometric coefficient $\beta<1$, Figure 4c, Table 1) was found between sperm length and body size (pronotum width) for CCNR, Pulau Ubin and Langkawi, and a negative and hypoallometric relationship was found for Central Peninsular MY. The adjusted R2 values for the linear model of all populations were low, signalling a weak correlation. In addition, the p-values of the slopes of the four linear models ( $\mathrm{P}>0.05$, Table 1) and 95\% CI (includes zero) suggests that body size is not a significant factor in explaining sperm length variation.

\section{Discussion}

\subsection{Sexual size dimorphism (SSD) varied among populations}

According to the differential equilibrium model, SSD arises from the equilibrium of three major evolutionary forces that acts differently on body size - sexual selection that selects for larger body size in males, fecundity selection that selects for larger body size in females and viability selection (e.g. natural selection) that select against large body size in both sexes, within general constraints (e.g. genetic, physiological etc.) (Blanckenhorn, 2005). In addition, Rensch's rule predicts that in species that exhibit male-biased SSD, the differences between the sexes increases with average body size and this is a well-supported phenomenon in vertebrates (Rensch, 1959).

Unlike birds and mammals, most insects exhibit female-biased SSD, where females have a larger body size (Blanckenhorn, 2005; Esperk et al. , 2007; Rudoy \& Ribera, 2017; Stillwell et al. , 2010). In beetles, only $9 \%$ of the reported species exhibit male-biased SSD while $72 \%$ exhibit female-biased SSD (Stillwell et al. , 2010). However, more specifically among the Onthophagus species, most do not display sexual 
size dimorphism (Pomfret \& Knell, 2006). In fact, a study of six Southeast Asian Onthophagus species, including O. Babirussa (from Peninsula Malaysia), reported no sexual size dimorphism (Goh \& Hashim, 2020). In our study, we documented significant male-biased SSD in both Singapore populations (CCNR and Pulau Ubin) and Langkawi (Figure 8 and appendix 4). Populations from Peninsula Malaysia had larger males but the difference between the sexes was not significant, thus replicating the results reported in Goh \& Hashim (2020).

Theory suggests that strong precopulatory sexual selection drives male-biased SSD in insects as larger body size in males have been widely documented to increase mating success due to female choice or male-male competition (Blanckenhorn, 2005; Puniamoorthy, Schäfer, \& Blanckenhorn, 2012; Stillwell et al. , 2010). In many Onthophagus dung beetles and related taxa, males compete to gain access to females and body size is a predominant factor in determining fighting success (Emlen, 1997; Moczek \& Emlen, 1999). However, the intensity of sexual acting male body size is not necessarily stronger than the fecundity selection acting on female body size. In beetles, larger females are generally able to produce larger and more offspring, thus accounting for the female-biased SSD observed in most species (Stillwell et al. , 2010). As such, the malebiased SSD in O. barbirussa is likely a derived trait that can be due to a relative increase in the intensity of sexual selection on male body size in this species.

Based on the Rensch's rule, one may predict that the SDI index or the difference between the sexes is most pronounced in the populations where body size is the largest i.e. the Malaysia populations. Instead, we document that SSD is most pronounced in the Singapore populations (CCNR and Pulau Ubin) where overall body size is the smaller. This is unlikely due to stronger sexual selection on males as the body size of males did not differ significantly between males of Singapore and Malaysia populations. Rather, larger SSD in Singapore was more likely due to weaker fecundity selection and/or stronger viability selection on females in Singapore as females were significantly smaller in Singapore than in Malaysian populations.

In Singapore, approximately $95 \%$ of forests were cleared over the last 200 years due to urbanisation, causing high local extinctions of fauna such as birds and mammals in forest habitats (Bickford et al. , 2010; Brook, Sodhl, \& Ng, 2003). Singapore's remaining forests are mostly degraded, highly fragmented and often subjected to high levels of disturbances, leading to a decrease in the general abundance of mammals (Bickford et al. , 2010; Lee et al. , 2009). Thus, there are fewer food and brood resources, leading to lesser opportunities for oviposition in female dung beetles in Singapore where the main sources of dung are likely from long-tailed macaques (Macaca fascicularis ) and wild boars (Sus scrofa) (Culot et al. , 2013). In contrast, the sites surveyed in Malaysia is located within larger stretches of forests that serve as a refuge for larger mammals not found in Singapore, such as Asian elephant (Elephas maximus) and Malayan Tapir (Tapirus indicus ), that are likely able to provide more food and brood resources for oviposition opportunities for female (Qie et al. , 2011; Rufino et al., 2010). Hence, lesser food resources in Singapore suggests that there could be a stronger viability selection on females in Singapore compared to Malaysia, leading to smaller female body size and male-biased SSD in Singapore populations. In addition, there could also be weaker fecundity selection on Singapore females because of lesser brood resources.

\subsection{Investment in precopulatory and postcopulatory traits varied among populations}

Sexual selection can occur before copulation, where males invest in precopulatory traits to increase mating opportunities and after copulation, where males invest in postcopulatory traits to increase chances of fertilising the ova of females (Birkhead \& Pizzari, 2002; Eberhard et al. , 2018). Our results show that all four populations showed strong positive static allometry for horn length where horns are disproportionately longer in larger individuals. In dung beetles, horns are weapons used in male-male combat to gain access to breeding females, strong precopulatory sexual selection on horns could explain the strong positive static allometry in male O. babirussa(Emlen, Lavine, \& Ewen-Campen, 2007; Simmons \& Ridsdill-Smith, 2011). Furthermore, compared to the allometric coefficient of classic case studies of sexually selected traits such as deer antlers $(\beta=1.86)$ and rhinoceros beetle horns $(\beta=4.15)$, the allometric coefficient for male $O$. babirussa horns was approximately twofold (Figure $9 \mathrm{a}, \beta=8.552-9.685$ ), further suggesting the presence of strong precopulatory sexual selection on horns (Kodric-Brown, Sibly \& Brown, 2006). 
Despite the importance of possessing larger horns in gaining access to females, males with small body sizes and small horns were still regularly sampled and seem to persist in wild populations (Figure 4a). In many Onthophagus species, males with small horns utilise alternative mating strategies in which they masquerade as females to sneak past guarding males with larger horns to gain access to breeding females (Simmons \& Ridsdill-Smith, 2011). Perhaps such an alternative mating strategy exists in O. babirussa, which could explain the phenotypic variation in horn length observed in wild-caught populations (Moczek \& Emlen, 2000).

Due to limited resources for growth and development, there may potentially be trade-offs in the investment of precopulatory and postcopulatory traits (Moczek \& Nijhout, 2004). As there was a high relative investment in horn length, a precopulatory trait, we hypothesized that there would be a low relative investment in postcopulatory traits such as testes weight and sperm length. We would also then expect a lower allometric coefficient compared to horn length allometry. As predicted, our results show a negative allometric relationship for sperm length $(\beta<1)$ for all populations, suggesting that there is a lower relative investment in sperm length than horns which could be due to weaker postcopulatory selection in maleO. babirussa. To test this, further studies would be needed to identify the rates of polyandry in wild-caught O.babirussa populations by determining paternity estimates of offspring to determine the intensity of postcopulatory sexual selection via sperm competition (McCullough, Buzatto, \& Simmons, 2017).

Interestingly, a positive allometric relationship for testes weight $(\beta=2.977)$ was found in Central Peninsula MY while the rest of the populations had a negative allometric relationship with testes weight $(\beta<1)$. Males from Central Peninsula MY have similar body sizes to those from Langkawi and Singapore, but with larger testes. This suggests that there is a higher relative investment in postcopulatory traits in Central Peninsula MY. This could be due to stronger postcopulatory selection arising from sperm competition, as many studies have shown that species under stronger selection often have larger testes (Simmons \& García-González, 2008). To test this, further studies would be needed to assess the level of sperm competition between males to determine if males in Central Peninsula MY have a competitive fertilisation advantage compared to the rest of the populations (Simmons \& García-González, 2008).

\section{Conclusions}

This study is the first report of male-biased SSD accompanied by intraspecific reproductive trait variation in the widespread, tropical dung beetle, Onthophagus babirussa . Contrary to the predictions of Rensch's rule, increased SSD is observed in populations with a lower average body size than those with a higher average body size. We suggest that the pronounced male-biased SSD may be due to weaker fecundity selection acting on females in the Singapore populations and not just than strong sexual selection on males. In order to resolve this, future studies should estimate fecundity selection on females as function of body size as well as sexual selection on male body size, under common garden experiments using more widespread populations across the region. In addition, population level differences in reproductive traits are likely affected by environmental conditions such as diet quality and developmental temperature (i.e. phenotypic plasticity). Phenotypic plasticity can differ between sexes and may even generate variation in SSD among populations. Hence, future studies could investigate the condition-dependence of reproductive traits in this species to better understand the observed population level differences in SSD.

\section{Table}

Table 1. Summary of allometric coefficients and model outputs for horn length, testes weight and sperm length allometry

\begin{tabular}{llllr}
\hline Population & Statistical Model & Allometric coefficient & Adjusted $\mathbf{R}^{\mathbf{2}}$ & $\mathbf{9 5}$ \\
\hline Horn length allometry & Horn length allometry & Horn length allometry & Horn length allometry & Ho \\
CCNR & Breakpoint & 9.500 & 0.824 & {$[7.6$} \\
Pulau Ubin & Breakpoint & 8.552 & 0.766 & {$[6.6$} \\
Central Peninsular MY & Breakpoint & 9.265 & 0.889 & {$[8.1$}
\end{tabular}




\begin{tabular}{lllll}
\hline Population & Statistical Model & Allometric coefficient & Adjusted $\mathbf{R}^{\mathbf{2}}$ & $\mathbf{9 5}$ \\
\hline Langkawi & Breakpoint & 9.685 & 0.899 & {$[8.8$} \\
Testes weight allometry & Testes weight allometry & Testes weight allometry & Testes weight allometry & Te \\
CCNR & Linear & -0.189 & -0.034 & {$[-7$.} \\
Pulau Ubin & Linear & 0.647 & -0.027 & {$[-5$.} \\
Central Peninsular MY & Linear & 2.977 & 0.001 & {$[-3$.} \\
Langkawi & Linear & 0.786 & -0.005 & {$[-1$.} \\
Sperm length allometry & Sperm length allometry & Sperm length allometry & Sperm length allometry & Sp \\
CCNR & Linear & 0.044 & -0.039 & {$[-0$.} \\
Pulau Ubin & Linear & 0.220 & 0.078 & {$[-0$.} \\
Central Peninsular MY & Linear & -0.201 & -0.063 & {$[-0$.} \\
Langkawi & Linear & -0.022 & -0.023 & {$[-0$.} \\
\hline
\end{tabular}

\section{Figure legends}

Figure 1. Map of sampling sites located in Singapore and Malaysia.

Figure 2. A schematic diagram highlighting the precopulatory (horn length and maximum pronotum width) and postcopulatory traits (sperm length and testes weight) that were measured in male $O$. babirussa .

Figure 3. Comparison of the average body size (pronotum width) of female and male O. babirussa across populations from Malaysia (MY: Langkawi: $\mathrm{n}=318$, Central Peninsular : $\mathrm{n}=97$ ) and Singapore (SG: $\mathrm{Pu}-$ lau Ubin: $\mathrm{n}=121$, CCNR: $\mathrm{n}=96$ ) to determine the presence of sexual size dimorphism (SSD). SSD varied across populations $\left(* *=P<0.01,{ }^{* * *}=P<0.001\right.$, ns $=$ not significant $)$.

Figure 4. log-log scatterplots to determine allometric relationship between body size and (a) horn length (CCNR: n=45, Pulau Ubin: $\mathrm{n}=61$, Central Peninsular MY: n=48, Langkawi: n=138) (b) testes weight (CCNR: $n=31$, Pulau Ubin: $n=37$, Central Peninsular MY: $n=21$, Langkawi: $n=122$ ) and (c) sperm length (CCNR: $\mathrm{n}=22$, Pulau Ubin: $\mathrm{n}=21$, Central Peninsular MY: n=8, Langkawi: $\mathrm{n}=39$ ).

\section{Figures}

\section{Hosted file}

image1.emf available at https://authorea.com/users/423265/articles/528771-sexualsize-dimorphism-and-male-reproductive-traits-vary-across-populations-of-a-tropicalrainforest-dung-beetle-species-onthophagus-babirussa

Figure 1. Map of sampling sites located in Singapore and Malaysia. 


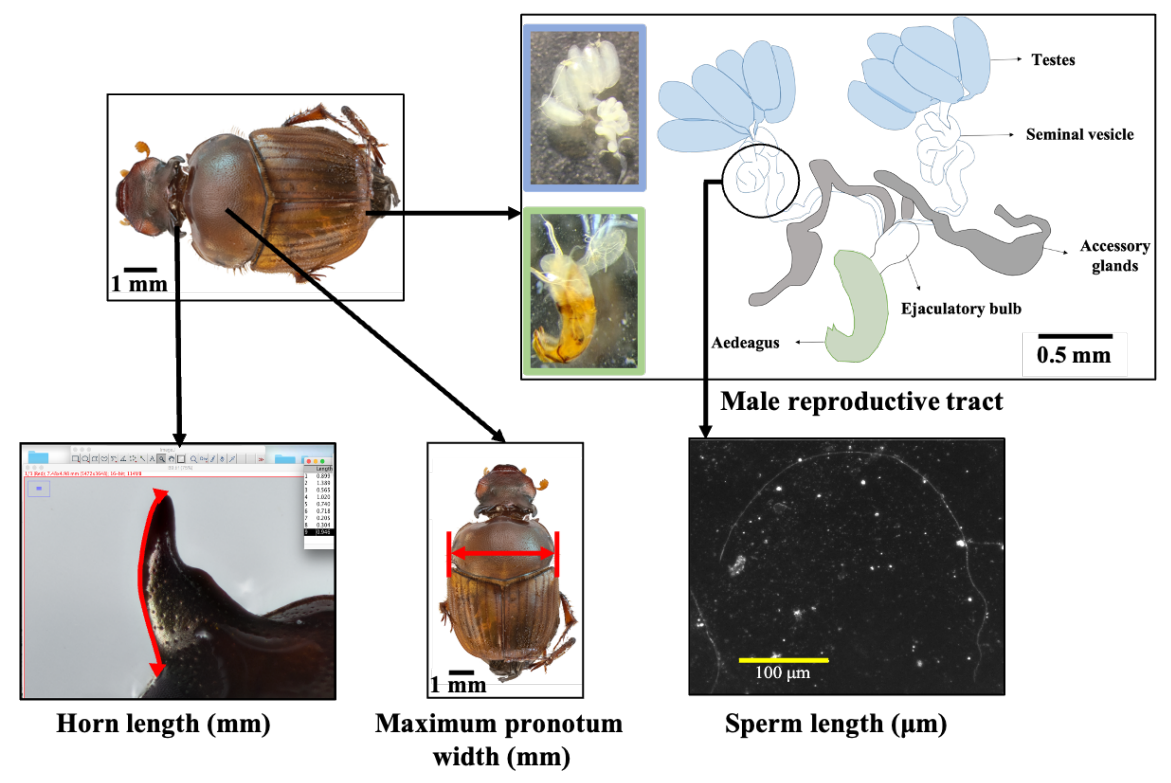

Figure 2. A schematic diagram highlighting the precopulatory (horn length and maximum pronotum width) and postcopulatory traits (sperm length and testes weight) that were measured in male O. babirussa .

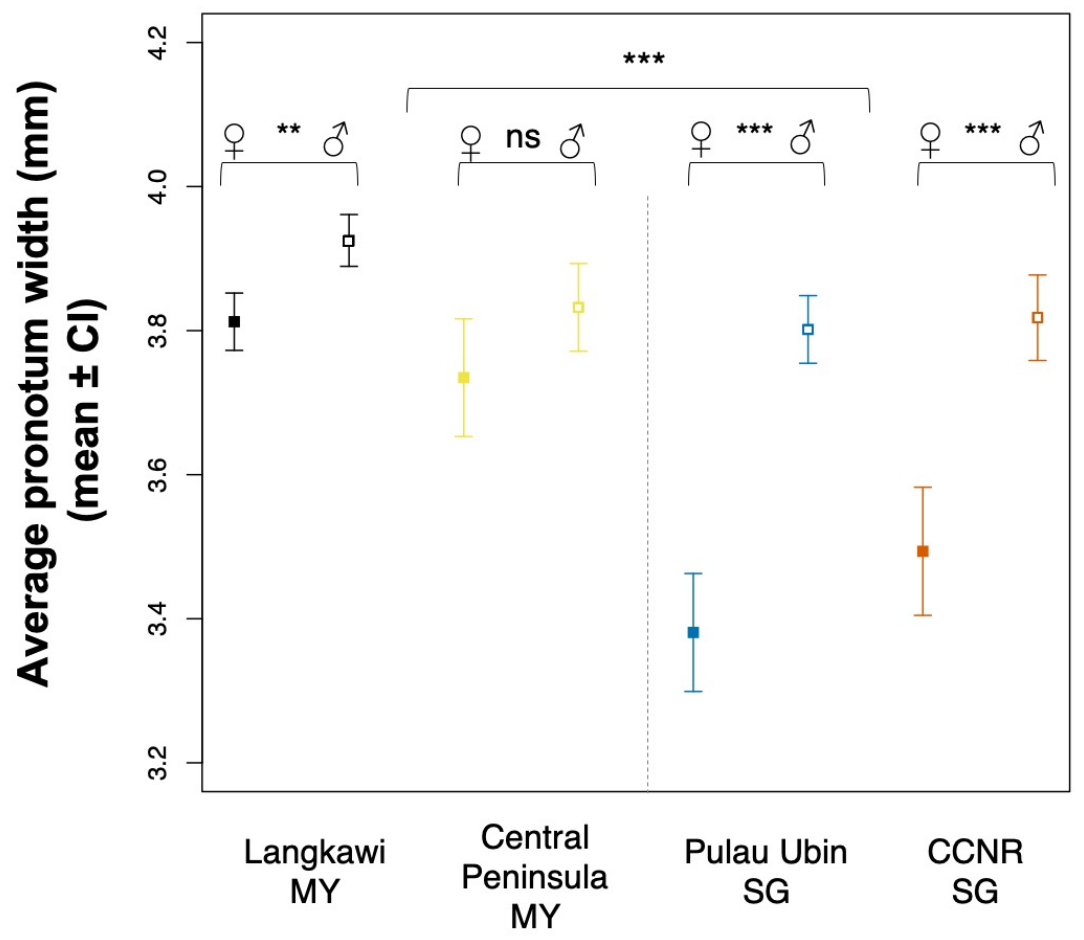

Populations 
Figure 3. Comparison of the average body size (pronotum width) of female and male $O$. babirussa across populations from Malaysia (MY: Langkawi: $\mathrm{n}=318$, Central Peninsular : $\mathrm{n}=97$ ) and Singapore (SG: Pulau Ubin: $n=121$, CCNR: $n=96$ ) to determine the presence of sexual size dimorphism (SSD). SSD varied across populations $(* *=P<0.01, * * *=P<0.001$, ns $=$ not significant $)$.

\section{Hosted file}

image4.emf available at https://authorea.com/users/423265/articles/528771-sexualsize-dimorphism-and-male-reproductive-traits-vary-across-populations-of-a-tropicalrainforest-dung-beetle-species-onthophagus-babirussa

Figure 4. log-log scatterplots to determine allometric relationship between body size and (a) horn length (CCNR: n=45, Pulau Ubin: $n=61$, Central Peninsular MY: n=48, Langkawi: $n=138$ ) (b) testes weight (CCNR: $n=31$, Pulau Ubin: $\mathrm{n}=37$, Central Peninsular MY: $\mathrm{n}=21$, Langkawi: $\mathrm{n}=122$ ) and (c) sperm length (CCNR: $\mathrm{n}=22$, Pulau Ubin: $\mathrm{n}=21$, Central Peninsular MY: $\mathrm{n}=8$, Langkawi: $\mathrm{n}=39$ ).

\section{Acknowledgments}

This research is supported by the Ministry of Education, Singapore, Tier 1 Research Grant (R154-000-C32114) as well as the Ah Meng Memorial Conservation fund (R-154-000-B65-720). Specimen collection in Singapore was conducted with the permission of the National Parks Board, under research permit number NP/RP18-034-2. Specimen collection in Malaysia was conducted by Thary Gazi Goh (local scientist) and collections were only carried out in unprotected areas that do not require a state permit for collection. We also thank members of the Reproductive Evolution Lab for assistance and support during this project.

\section{Data Accessibility:}

The $\mathrm{R}$ scripts and data that support the findings of this study are openly available in Dryad at reference number The DNA sequences are available in Genbank:

\section{References}

Andersson, M., 1994. Sexual selection. Princeton University Press.

Bickford, D., Ng, T.H., Qie, L., Kudavidanage, E.P., Bradshaw, C.J.A., 2010. Forest fragment and breeding habitat characteristics explain frog diversity and abundance in Singapore. Biotropica. https://doi.org/10.1111/j.1744-7429.2009.00542.x

Birkhead, T.R., Pizzari, T., 2002. Postcopulatory sexual selection. Nat. Rev. Genet. https://doi.org/10.1038/nrg774

Blanckenhorn, W.U., 2005. Behavioral causes and consequences of sexual size dimorphism. Ethology. https://doi.org/10.1111/j.1439-0310.2005.01147.x

Blanckenhorn, W.U., Kraushaar, U.R.S., Teuschl, Y., Reim, C., 2004. Sexual selection on morphological and physiological traits and fluctuating asymmetry in the black scavenger fly Sepsis cynipsea. J. Evol. Biol. 17, 629-641. https://doi.org/10.1111/j.1420-9101.2004.00693.x

Blanckenhorn, W.U., Meier, R., Teder, T., 2007. Rensch's rule in insects: Patterns among and within species, in: Sex, Size and Gender Roles: Evolutionary Studies of Sexual Size Dimorphism. https://doi.org/10.1093/acprof:oso/9780199208784.003.0007

Brook, B.W., Sodhl, N.S., Ng, P.K.L., 2003. Catastrophic extinctions follow deforestation in Singapore. Nature. https://doi.org/10.1038/nature01795

Cox, R.M., Calsbeek, R., 2010. Sex-specific selection and intraspecific variation in sexual size dimorphism. Evolution (N. Y). 64, 798-809. https://doi.org/10.1111/j.1558-5646.2009.00851.x 
Culot, L., Bovy, E., Zagury Vaz-de-Mello, F., Guevara, R., Galetti, M., 2013. Selective defaunation affects dung beetle communities in continuous Atlantic rainforest. Biol. Conserv. https://doi.org/10.1016/j.biocon.2013.04.004

Dale, J., Dunn, P.O., Figuerola, J., Lislevand, T., Székely, T., Whittingham, L.A., 2007. Sexual selection explains Rensch's rule of allometry for sexual size dimorphism. Proc. R. Soc. B Biol. Sci. 274, 2971-2979. https://doi.org/10.1098/rspb.2007.1043

Eberhard, W.G., Rodríguez, R.L., Huber, B.A., Speck, B., Miller, H., Buzatto, B.A., Machado, G., 2018. Sexual selection and static allometry: The importance of function. Q. Rev. Biol. https://doi.org/10.1086/699410

Emlen, D. J., 1997. Diet alters male horn allometry in the beetle Onthophagus acuminatus (Coleoptera: Scarabaeidae). Proc. R. Soc. B Biol. Sci. https://doi.org/10.1098/rspb.1997.0081

Emlen, Douglas J., 1997. Alternative reproductive tactics and male-dimorphism in the horned beetle Onthophagus acuminatus (Coleoptera: Scarabaeidae). Behav. Ecol. Sociobiol. 41, 335-341. https://doi.org/10.1007/s002650050393

Emlen, D.J., 1994. Environmental control of horn length dimorphism in the beetle Onthophagus acuminatus (Coleoptera: Scarabaeidae). Proc. R. Soc. B Biol. Sci. https://doi.org/10.1098/rspb.1994.0060

Emlen, D.J., Lavine, L.C., Ewen-Campen, B., 2007. On the origin and evolutionary diversification of beetle horns. Proc. Natl. Acad. Sci. U. S. A. https://doi.org/10.1073/pnas.0701209104

Esperk, T., Tammaru, T., Nylin, S., Teder, T., 2007. Achieving high sexual size dimorphism in insects: Females add instars. Ecol. Entomol. https://doi.org/10.1111/j.1365-2311.2007.00872.x

Fairbairn, D.J., 1997. Allometry for sexual size dimorphism: Pattern and process in the coevolution of body size in males and females. Annu. Rev. Ecol. Syst. https://doi.org/10.1146/annurev.ecolsys.28.1.659

Foottit, R.G., H. Adler, P., 2009. Insect biodiversity: science and society., John Wiley \& Sons. https://doi.org/10.1002/9781118945582

Fraija-Fernández, N., Hernández-Hortelano, A., Ahuir-Baraja, A.E., Raga, J.A., Aznar, F.J., 2018. Taxonomic status and epidemiology of the mesoparasitic copepod Pennella balaenoptera in cetaceans from the western Mediterranean. Dis. Aquat. Organ. 128, 249-258. https://doi.org/10.3354/dao03226

Garcia-Gonzalez, F., Simmons, L.W., 2011. Good genes and sexual selection in dung beetles (Onthophagus taurus): Genetic variance in egg-to-adult and adult viability. PLoS One 6. https://doi.org/10.1371/journal.pone.0016233

García-González, F., Simmons, L.W., 2007. Shorter sperm confer higher competitive fertilization success. Evolution (N. Y). https://doi.org/10.1111/j.1558-5646.2007.00084.x

Geller, J., Meyer, C., Parker, M., Hawk, H., 2013. Redesign of PCR primers for mitochondrial cytochrome c oxidase subunit I for marine invertebrates and application in all-taxa biotic surveys. Mol. Ecol. Resour. 13, 851-861. https://doi.org/10.1111/1755-0998.12138

Goh, T.G., 2014. PRELIMINARY SURVEY OF DUNG BEETLE DIVERSITY IN KRAU WILDLIFE RESERVE, PAHANG, MALAYSIA. J. Wildl. Park. 28, 11-36.

Goh, T.G., Hashim, R., 2020. Trait responses of Peninsular Malaysian dung beetles (Scarabaeidae: Scarabaeinae) to the loss of megafauna dung. J. Trop. Ecol. https://doi.org/10.1017/S0266467419000270

Hebert, P.D.N., Cywinska, A., Ball, S.L., DeWaard, J.R., 2003. Biological identifications through DNA barcodes. Proc. R. Soc. B Biol. Sci. 270, 313-321. https://doi.org/10.1098/rspb.2002.2218

Howden, H.F., Nealis, V.G., 1975. Effects of Clearing in a Tropical Rain Forest on the Composition of the Coprophagous Scarab Beetle Fauna (Coleoptera). Biotropica 7, 77. https://doi.org/10.2307/2989750 
Kijimoto, T., Costello, J., Tang, Z., Moczek, A.P., Andrews, J., 2009. EST and microarray analysis of horn development in Onthophagus beetles. BMC Genomics 10, 504. https://doi.org/10.1186/1471-2164-10-504

Knapp, M., Knappová, J., 2013. Measurement of Body Condition in a Common Carabid Beetle, Poecilus cupreus : A comparison of Fresh Weight, Dry Weight, and Fat Content . J. Insect Sci. 13, 1-10. https://doi.org/10.1673/031.013.0601

Knell, R.J., 2009. On the analysis of non-linear allometries. Ecol. Entomol. https://doi.org/10.1111/j.13652311.2008.01022.x

Kodric-Brown, A., Sibly, R.M., Brown, J.H., 2006. The allometry of ornaments and weapons. Proc. Natl. Acad. Sci. U. S. A. 103, 8733-8738. https://doi.org/10.1073/pnas.0602994103

Kudavidanage, E.P., Qie, L., Lee, J.S.H., 2012. Linking biodiversity and ecosystem functioning of dung beetles in south and Southeast Asian tropical rainforests. Raffles Bull. Zool. 141-154.

Larsen, T.H., Forsyth, A., 2005. Trap spacing and transect design for dung beetle biodiversity studies. Biotropica 37, 322-325. https://doi.org/10.1111/j.1744-7429.2005.00042.x

Lee, J.S.H., Lee, I.Q.W., Lim, S.L.H., Huijbregts, J., Sodhi, N.S., 2009. Changes in dung beetle communities along a gradient of tropical forest disturbance in South-East Asia. J. Trop. Ecol. https://doi.org/10.1017/S0266467409990174

Leigh, J.W., Bryant, D., 2015. POPART: Full-feature software for haplotype network construction. Methods Ecol. Evol. 6, 1110-1116. https://doi.org/10.1111/2041-210X.12410

Lemon, J., 2006. Plotrix: a package in the red light district of R.

Leray, M., Yang, J.Y., Meyer, C.P., Mills, S.C., Agudelo, N., Ranwez, V., Boehm, J.T., Machida, R.J., 2013. A new versatile primer set targeting a short fragment of the mitochondrial COI region for metabarcoding metazoan diversity: Application for characterizing coral reef fish gut contents. Front. Zool. 10, 1-14. https://doi.org/10.1186/1742-9994-10-34

Liao, W.B., Liu, W.C., Merilä, J., 2015. Andrew meets Rensch: sexual size dimorphism and the inverse of Rensch's rule in Andrew's toad (Bufo andrewsi). Oecologia 177, 389-399. https://doi.org/10.1007/s00442014-3147-8

Lovich, J.E., Gibbons, J.W., 1990. Age at Maturity Influences Adult Sex Ratio in the Turtle Malaclemys terrapin. Oikos 59, 126. https://doi.org/10.2307/3545132

Lucigen, 2018. QuickExtract ${ }^{\mathrm{TM}}$ Plant DNA Extraction Solution [WWW Document]. URL https://www.lucigen.com/docs/manuals/MA150E-QuickExtract-DNA-Solution.pdf

McCullough, E.L., Buzatto, B.A., Simmons, L.W., 2017. Benefits of polyandry: Molecular evidence from field-caught dung beetles. Mol. Ecol. https://doi.org/10.1111/mec.14127

Meier, R., Wong, W., Srivathsan, A., Foo, M., 2016. \$1 DNA barcodes for reconstructing complex phenomes and finding rare species in specimen-rich samples. Cladistics. https://doi.org/10.1111/cla.12115

Meiklejohn, K.A., Wallman, J.F., Dowton, M., 2011. DNA-based identification of forensically important Australian Sarcophagidae (Diptera). Int. J. Legal Med. 125, 27-32. https://doi.org/10.1007/s00414-0090395-y

Moczek, A.P., 1998. Horn polyphenism in the beetle Onthophagus taurus: Larval diet quality and plasticity in parental investment determine adult body size and male horn morphology. Behav. Ecol. https://doi.org/10.1093/beheco/9.6.636

Moczek, A.P., Emlen, D.J., 2000. Male horn dimorphism in the scarab beetle, Onthophagus taurus: Do alternative reproductive tactics favour alternative phenotypes? Anim. Behav. https://doi.org/10.1006/anbe.1999.1342 
Moczek, A.P., Emlen, D.J., 1999. Proximate determination of male horn dimorphism in the beetle Onthophagus taurus (Coleoptera: Scarabaeidae). J. Evol. Biol. 12, 27-37. https://doi.org/10.1046/j.14209101.1999.00004.x

Moczek, A.P., Nijhout, H.F., 2004. Trade-offs during the development of primary and secondary sexual traits in a horned beetle. Am. Nat. https://doi.org/10.1086/381741

Muggeo, V.M.R., 2008. segmented: an R Package to Fit Regression Models with Broken-Line Relationships.

Panhuis, T.M., Butlin, R., Zuk, M., Tregenza, T., 2001. Sexual selection and speciation. Trends Ecol. Evol. https://doi.org/10.1016/S0169-5347(01)02160-7

Parrett, A.J.M., Slade, E.M., Knell, R.J., 2021. Morph-specific investment in testes mass in a trimorphic beetle, Proagoderus watanabei. bioRxiv 2021.05.09.443318. https://doi.org/10.1101/2021.05.09.443318

Parrett, J.M., Knell, R.J., 2018. The effect of sexual selection on adaptation and extinction under increasing temperatures. Proc. R. Soc. B Biol. Sci. 285. https://doi.org/10.1098/rspb.2018.0303

Parrett, J.M., Mann, D.J., Chung, A.Y.C., Slade, E.M., Knell, R.J., 2019. Sexual selection predicts the persistence of populations within altered environments. Ecol. Lett. https://doi.org/10.1111/ele.13358

Parzer, H.F., Moczek, A.P., 2008. Rapid antagonistic coevolution between primary and secondary sexual characters in horned beetles. Evolution (N. Y). https://doi.org/10.1111/j.1558-5646.2008.00448.x

Piross, I.S., Harnos, A., Rózsa, L., 2019. Rensch's rule in avian lice: contradictory allometric trends for sexual size dimorphism. Sci. Rep. 9, 1-9. https://doi.org/10.1038/s41598-019-44370-5

Pomfret, J.C., Knell, R.J., 2006. Sexual selection and horn allometry in the dung beetle Euoniticellus intermedius. Anim. Behav. https://doi.org/10.1016/j.anbehav.2005.05.023

Priawandiputra, W., Tsuji, Y., Widayati, K.A., Suryobroto, B., 2020. Dung beetle assemblages in lowland forests of pangandaran nature reserve, West Java, Indonesia. Biodiversitas. https://doi.org/10.13057/biodiv/d210210

Puniamoorthy, N., Schäfer, M.A., Blanckenhorn, W.U., 2012. Sexual selection accounts for the geographic reversal of sexual size dimorphism in the dung fly, sepsis punctum (diptera: Sepsidae). Evolution (N. Y). https://doi.org/10.1111/j.1558-5646.2012.01599.x

Qie, L., Lee, T.M., Sodhi, N.S., Lim, S.L.H., 2011. Dung beetle assemblages on tropical land-bridge islands: Small island effect and vulnerable species. J. Biogeogr. https://doi.org/10.1111/j.1365-2699.2010.02439.x

Rensch, B., 1959. Evolution Above the Species Level, Evolution Above the Species Level. Methuen and Co.

Rossi, M.N., Haga, E.B., 2019. Testing rensch's rule in Acanthoscelides macrophthalmus, a seed-feeding beetle infesting Leucaena leucocephala plants. Can. J. Zool. 97, 304-311. https://doi.org/10.1139/cjz-2018-0063

Rudoy, A., Ribera, I., 2017. Evolution of sexual dimorphism and Rensch's rule in the beetle genus Limnebius (Hydraenidae): Is sexual selection opportunistic? PeerJ. https://doi.org/10.7717/peerj.3060

Rufino, M.B.M., Magintan, D., Ngau, C., Abu Zahrim, I., Hamidi, J., Zainal, A.M., Idlan, R., Abdul Kadir, A.H., Dennis, T.C.Y., Fauzul Azim, Z.A., 2010. Mammals of Temenggor Forest Reserve: Evidence through Camera Trapping, in: Proceeding of National Biodiversity Seminar.

Silva, D.P., Vilela, B., Buzatto, B.A., Moczek, A.P., Hortal, J., 2016. Contextualized niche shifts upon independent invasions by the dung beetle Onthophagus taurus. Biol. Invasions. https://doi.org/10.1007/s10530016-1204-4

Simmons, L.W., García-González, F., 2008. Evolutionary reduction in testes size and competitive fertilization success in response to the experimental removal of sexual selection in dung beetles. Evolution (N. Y). https://doi.org/10.1111/j.1558-5646.2008.00479.x 
Simmons, L.W., Kotiaho, J.S., 2002. EVOLUTION OF EJACULATES: PATTERNS OF PHENOTYPIC AND GENOTYPIC VARIATION AND CONDITION DEPENDENCE IN SPERM COMPETITION TRAITS. Evolution (N. Y). https://doi.org/10.1554/0014-3820(2002)056[1622:eoepop]2.0.co;2

Simmons, L.W., Ridsdill-Smith, T.J., 2011. Ecology and Evolution of Dung Beetles, Ecology and Evolution of Dung Beetles. https://doi.org/10.1002/9781444342000

Srivathsan, A., Meier, R., 2012. On the inappropriate use of Kimura-2-parameter (K2P) divergences in the DNA-barcoding literature. Cladistics 28, 190-194. https://doi.org/10.1111/j.1096-0031.2011.00370.x

Stillwell, R.C., Blanckenhorn, W.U., Teder, T., Davidowitz, G., Fox, C.W., 2010. Sex differences in phenotypic plasticity affect variation in sexual size dimorphism in insects: From physiology to evolution. Annu. Rev. Entomol. https://doi.org/10.1146/annurev-ento-112408-085500

Székely, T., Freckleton, R.P., Reynolds, J.D., 2004. Sexual selection explains Rensch's rule of size dimorphism in shorebirds. Proc. Natl. Acad. Sci. U. S. A. 101, 12224-12227. https://doi.org/10.1073/pnas.0404503101

Teder, T., Tammaru, T., 2005. Sexual size dimorphism within species increases with body size in insects. Oikos 108, 321-334. https://doi.org/10.1111/j.0030-1299.2005.13609.x

Toh, K.X., 2019. Reproductive trait variation across populations of the dung beetle, Onthophagus cf. babirussa. National Universtiy of Singapore.

Waugh, J., 2007. DNA barcoding in animal species: Progress, potential and pitfalls. BioEssays. https://doi.org/10.1002/bies.20529

Werner, M., Simmons, L.W., 2011. Ultrastructure of spermatozoa of Onthophagus taurus (Coleoptera, Scarabaeidae) exhibits heritable variation. Naturwissenschaften. https://doi.org/10.1007/s00114-011-0763-6

Wickham, H., 2016. ggplot2: Elegant Graphics for Data Analysis.

Wickham, H., François, R., Henry, L., Müller, K., 2020. dplyr: A Grammar of Data Manipulation.

Zhang, J., Kobert, K., Flouri, T., Stamatakis, A., 2014. PEAR: A fast and accurate Illumina Paired-End reAd mergeR. Bioinformatics. https://doi.org/10.1093/bioinformatics/btt593

\section{Appendix 1}

Table S1. Summary of sampling site locations. Sampling in Singapore was conducted with the permission of the National Parks Board, under permit numbers NP/RP18-034c and NP/RP18-034-1. Malaysian specimens were collected with the help of Thary Gazi Goh from the University of Malaya, and sampling was conducted in unprotected forests that do not require permits.

\begin{tabular}{lll}
\hline Sampling site & Country & Coordinates \\
\hline Mandai & Singapore & $1.407^{\circ} \mathrm{N}, 103.783^{\circ} \mathrm{E} 1.400^{\circ} \mathrm{N}$, \\
& & $103.777^{\circ} \mathrm{E}$ \\
Chestnut Nature Park & Singapore & $1.376^{\circ} \mathrm{N}, 103.782^{\circ} \mathrm{E}$ \\
Rifle Range & Singapore & $1.355^{\circ} \mathrm{N}, 103.799^{\circ} \mathrm{E}$ \\
Windsor Nature Park & Singapore & $1.359^{\circ} \mathrm{N}, 103.826^{\circ} \mathrm{E}$ \\
Pulau Ubin & Singapore & $1.412^{\circ} \mathrm{N}, 103.957^{\circ} \mathrm{E}$ \\
Langkawi & Malaysia & $6.433^{\circ} \mathrm{N}, 99.708^{\circ} \mathrm{E}$ \\
Kenyir & Malaysia & $4.962^{\circ} \mathrm{N}, 102.812^{\circ} \mathrm{E}$ \\
Temenggor & Malaysia & $5.539^{\circ} \mathrm{N}, 101.328^{\circ} \mathrm{E}$ \\
Gombak & Malaysia & $3.324^{\circ} \mathrm{N}, 101.752^{\circ} \mathrm{E}$ \\
\hline
\end{tabular}




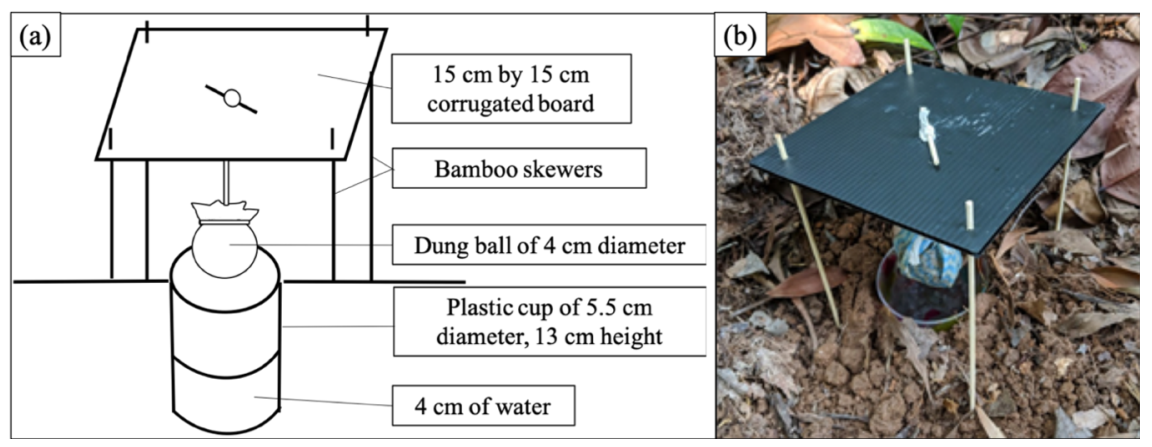

Figure S1. (a) Diagram and (b) photograph showing structure and components of dung-baited pitfall traps. Human dung was wrapped in cloth to form a "dung ball" of $4 \mathrm{~cm}$ in diameter and suspended approximately $4 \mathrm{~cm}$ above a buried plastic cup using cotton twine and a shelter made of $15 \mathrm{~cm}$ by $15 \mathrm{~cm}$ corrugated board. Buried plastic cups were filled with $4 \mathrm{~cm}$ of water to wet the wings of dung beetles that have fallen in to prevent the beetles from escaping.

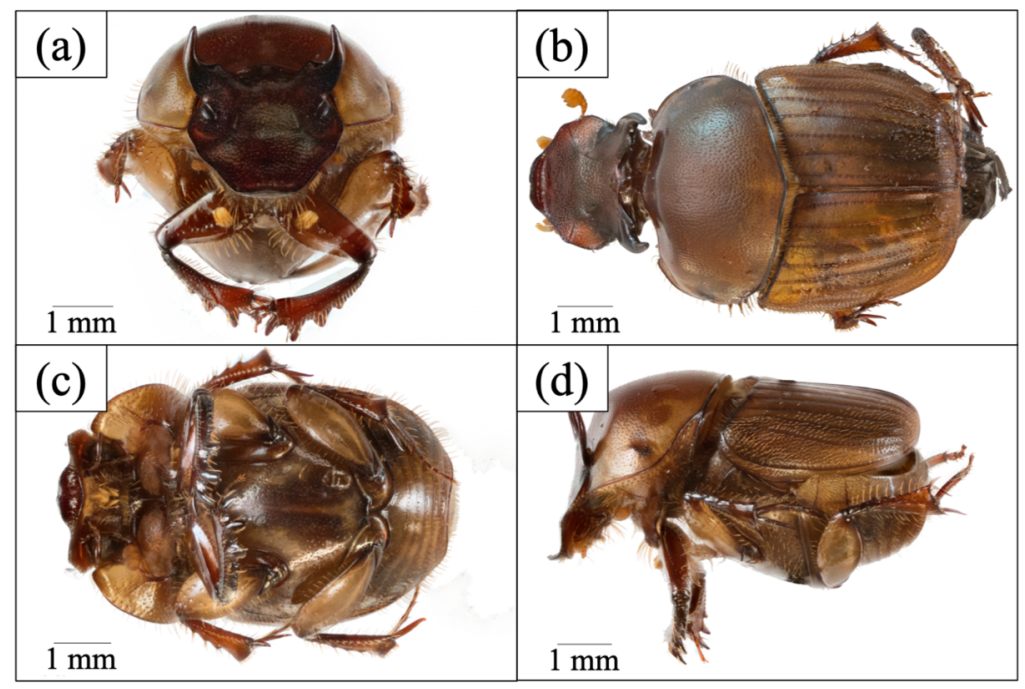

Figure S2. Images of male O. babirussa in four angles (a) Anterior (b) Dorsal (c) Ventral (d) Lateral 


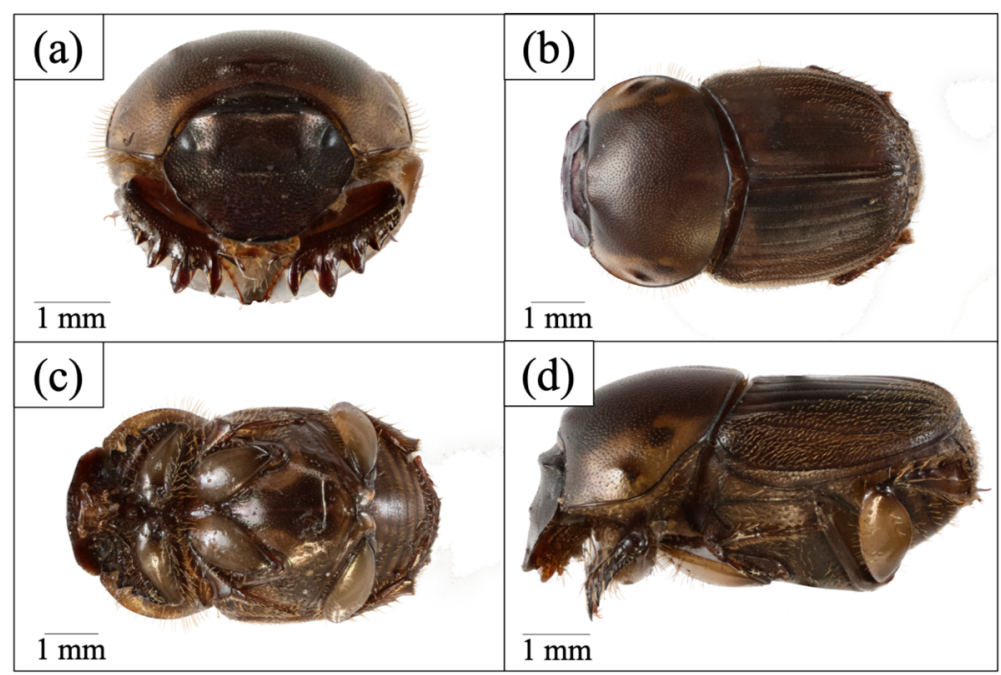

Figure S3. Images of female O. babirussa in four angles (a) Anterior (b) Dorsal (c) Ventral (d) Lateral

\section{Appendix 2}

\section{NGS and Sequence Analysis}

According to the manufacturer's instructions, the PCR products underwent bead cleanup to purify the products. Subsequently, the products were quantified, pooled in equimolar ratios and submitted for library preparation by Genome Institute of Singapore. Then, Next-Generation Sequencing (NGS) was conducted using MiSeq sequencing platform to obtain 313bp fragment of COI gene.

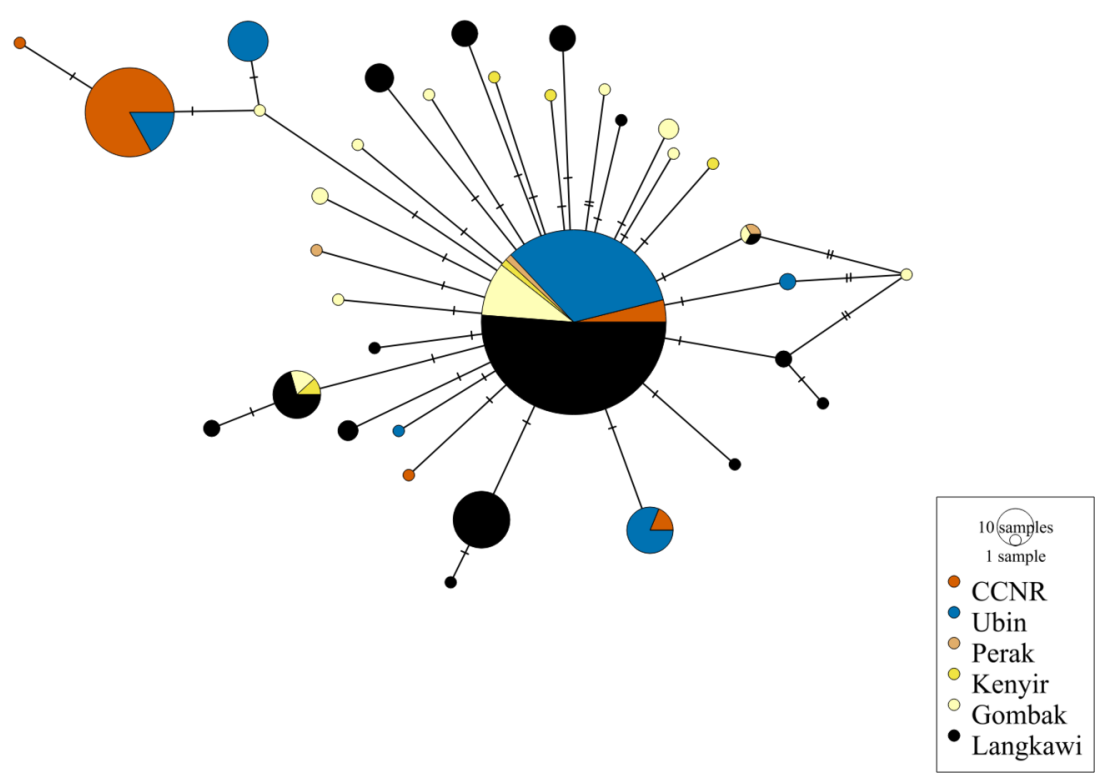

Sequence analysis was then conducted with reference to the analysis pipeline detailed by (Meier et al., 2016). The reads from the Paired-end were merged by the software PEAR 0.9.6 (Zhang et al. , 2014).. The reads 
of each PCR products were then matched to their specific template specimen which was achieved due to primer pair combination that were uniquely labelled. A python script by (Srivathsan, unpublished) was used to 1) demultiplex data, 2) tally the reads for each sample, 3) identify and cluster identical reads into groups, 4) identify dominant groups of reads and combine with variants that were otherwise of identical length and lastly 5) tally the reads found in the group showing highest identity and compare with the group showing the next highest identity (Meier et al., 2016). Quality control was carried out by a set of criteria namely more than 50x read count, more than 10x barcode count and for the number of dominant reads to be five times or more than second most dominant reads (Meier et al., 2016). This was to ensure that coverage attributed to each barcode was sufficient and not from confounding sequences such as contaminant DNA fragments. In addition, quality control rejects dominant sequences that may have arisen out of amplification error in the PCR step. Next, the sequences that passed the quality control were entered into the search query in Basic Local Alignment Search Tool (BLAST) to search for sequences that match $>97 \%$ to non-Onthophagus taxa, which were contaminant sequences and thus eliminated from analysis. After quality control, MEGA7, an online software, was used to align the sequences to ensure that there were no stop codons. Then, a new Python script (Srivathsan, unpublished) was used to construct $\mathrm{c}$ and a threshold of $3 \%$ which is widely used to distinguish between species in literatures on insects (Hebert et al., 2003; Srivathsan \& Meier, 2012).

Figure S4. Haplotype map based on 434 specimens across all sampling sites, CCNR $(\mathrm{n}=64)$, Ubin $(\mathrm{n}=122)$, Perak $(\mathrm{n}=5)$, Kenyir $(\mathrm{n}=8)$, Gombak $(\mathrm{n}=40)$, Langkawi $(\mathrm{n}=195)$.

\section{Appendix 3}

\section{Model selection for log-log scatterplot of horn length against pronotum width}
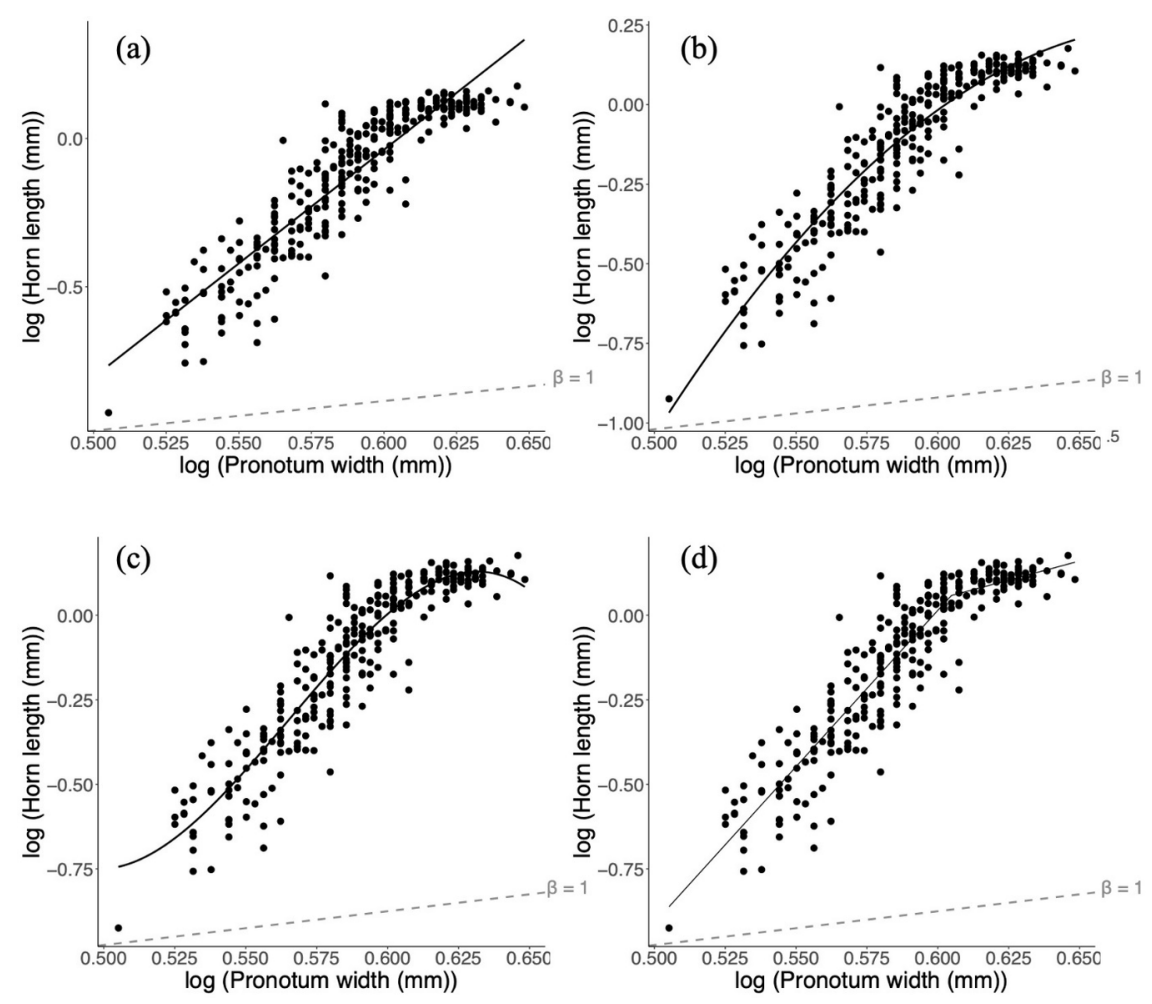

Figure S5. log-log scatterplot to determine the allometric relationship between horn length and body size (pronotum width) in male O.babirussa from Singapore. Following recommendations by Knell (2009), I fitted (a) linear model (b) quadratic model (c) cubic model and (d) breakpoint model using the R package 
segmented (Muggeo, 2008) to the pooled data with all four populations to characterise the horn length-body size $(\mathrm{n}=292)$.

Table S2. Akaike information criterion (AIC) to compare the four models

\begin{tabular}{llll}
\hline Type of model & df & AIC & $\Delta$ AIC \\
\hline Linear model & 3 & -507.8343 & 61.9236 \\
Quadratic model & 4 & -548.6784 & 21.0795 \\
Cubic model & 5 & -569.5630 & 0.1949 \\
Breakpoint model & 5 & -569.7579 & 0 \\
\hline
\end{tabular}

\section{Appendix 4}

Horn length allometry plots with best fit model for each population
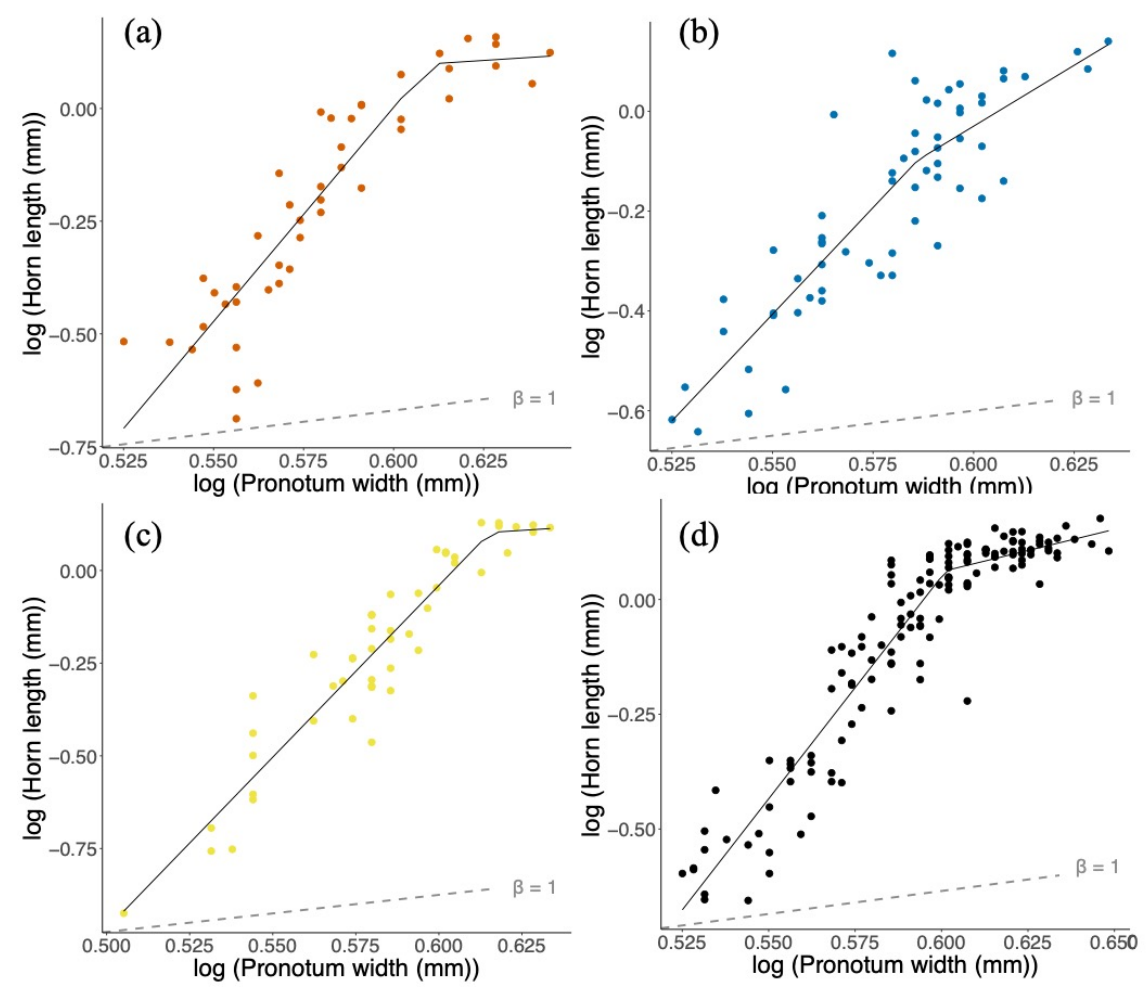

Figure S6. log-log scatterplot to determine the allometric relationship between horn length and body size (pronotum width) in male O. babirussa from (a) CCNR ( $\mathrm{n}=45)$, (b) Pulau Ubin ( $\mathrm{n}=61)$, (c) Central Peninsular MY (n=48) and (d) Langkawi $(\mathrm{n}=138)$, using the breakpoint model. 

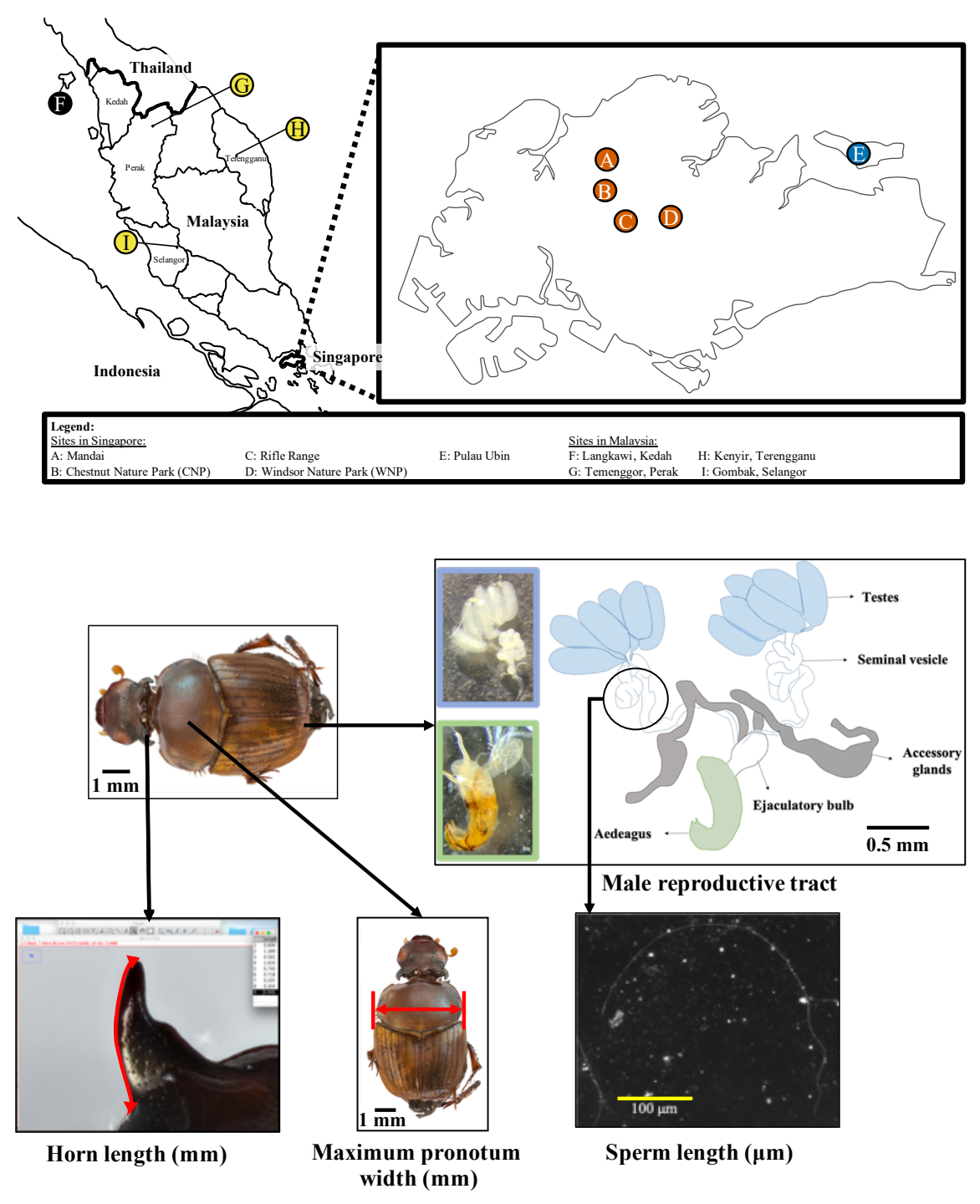


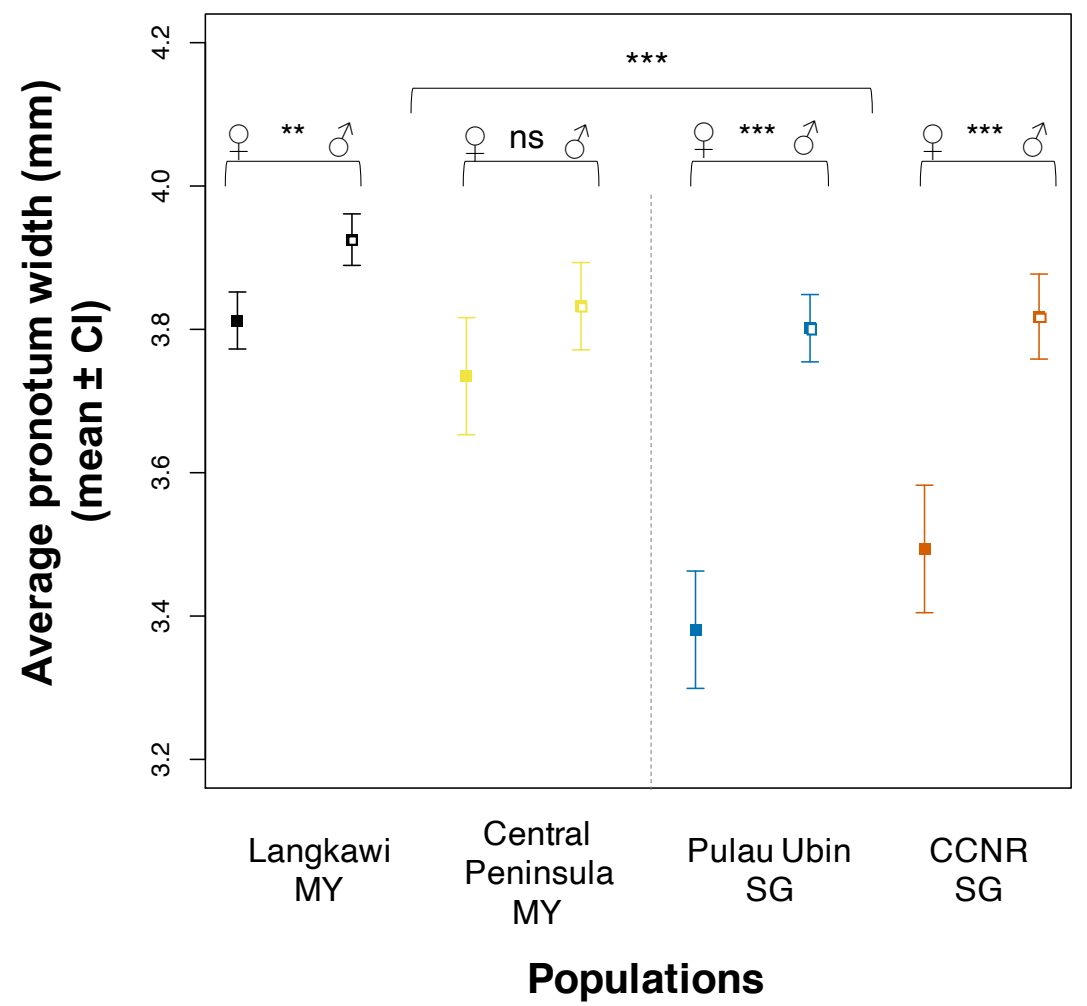



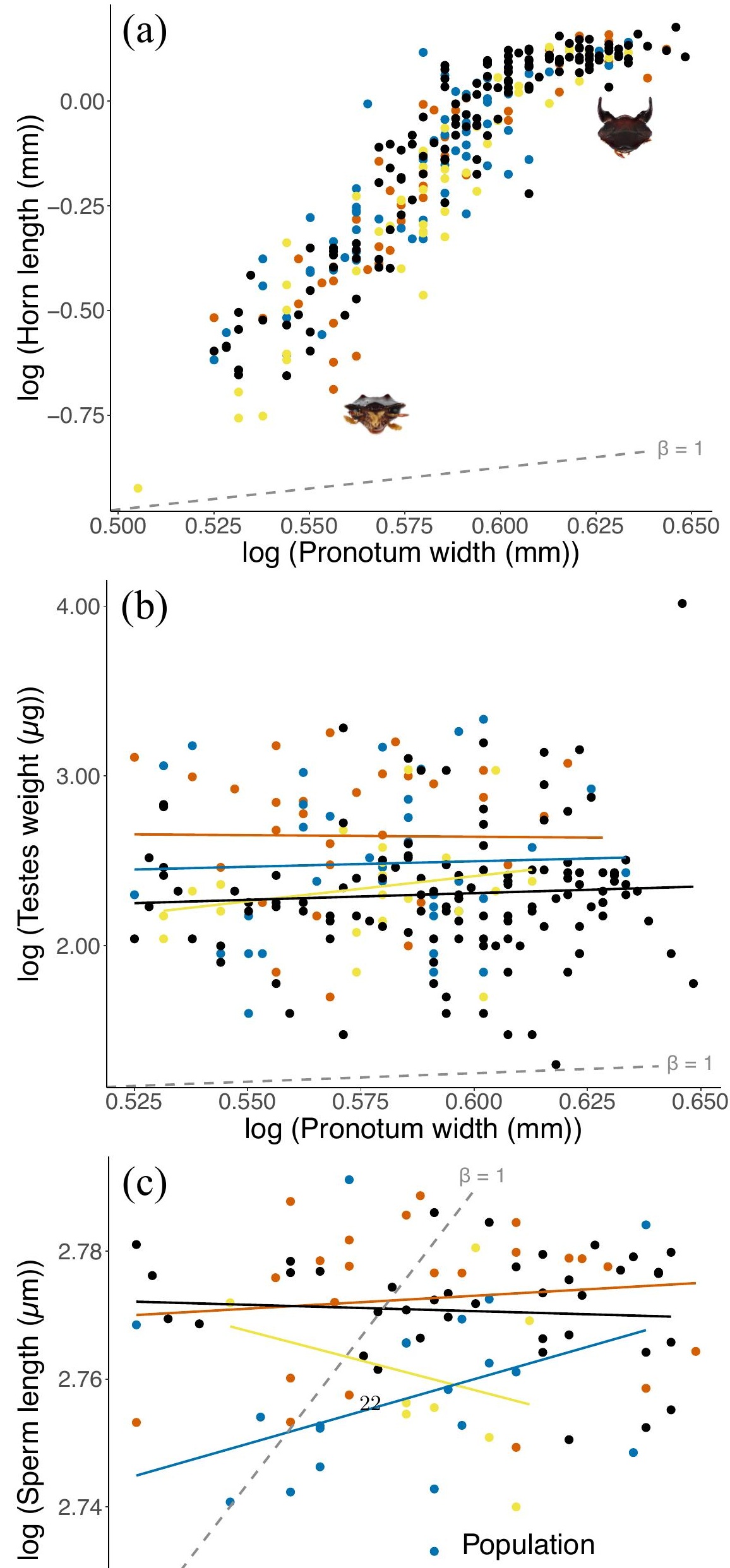